AperTO - Archivio Istituzionale Open Access dell'Università di Torino

A transient kinetic study between signaling proteins: the case of the MEK-ERK interaction

This is a pre print version of the following article:

Original Citation:

Availability:

This version is available http://hdl.handle.net/2318/89132

since 2016-10-10T10:24:20Z

Published version:

DOI:10.1039/c1sc00268f

Terms of use:

Open Access

Anyone can freely access the full text of works made available as "Open Access". Works made available under a Creative Commons license can be used according to the terms and conditions of said license. Use of all other works requires consent of the right holder (author or publisher) if not exempted from copyright protection by the applicable law. 


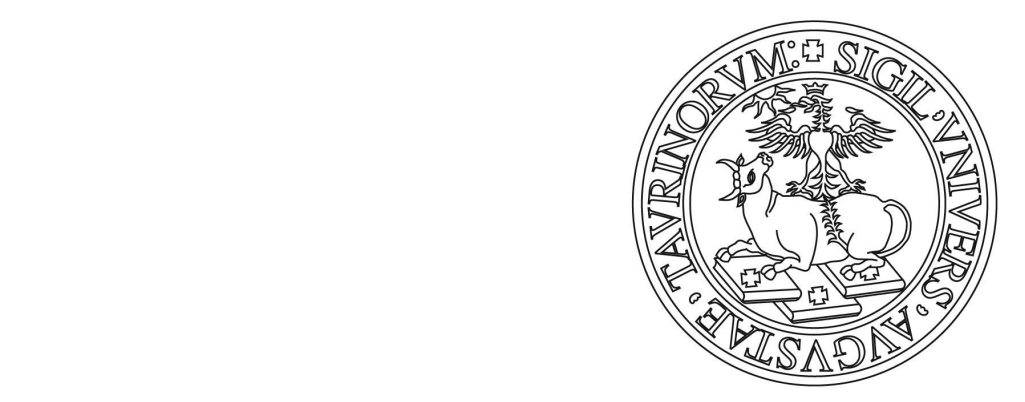

\section{UNIVERSITÀ DEGLI STUDI DI TORINO}

This is an author version of the contribution published on:

Questa è la versione dell'autore dell'opera:

[Chem. Sci., 2, 2011, 10.1039/c1sc00268f]

ovvero [Nadia Barbero, Lucia Napione, Sonja Visentin, Maria Alvaro, Andrea Veglio,

Federico Bussolino, Guido Viscardi, 2, RSC, 2011, pagg.1804-1809]

The definitive version is available at:

La versione definitiva è disponibile alla URL:

[http://pubs.rsc.org/en/content/articlelanding/2011/sc/c1sc00268f\#!divAbstract] 


\title{
A transient kinetic study between signaling proteins: the case of MEK- ERK interaction
}

\author{
Nadia Barbero, ${ }^{*, a,}+$ Lucia Napione, ${ }^{*, b}$, + Sonja Visentin, ${ }^{\mathrm{c}}$ Maria Alvaro, ${ }^{\mathrm{b}}$ Andrea Veglio, ${ }^{\mathrm{b}}$ Federico \\ Bussolino $^{\mathrm{b}}$ and Guido Viscardi ${ }^{\mathrm{a}}$
}

\author{
${ }_{5}$ Received (in $\left.X X X, X X X\right)$ Xth $X X X X X X X X X 20 X X$, Accepted Xth $X X X X X X X X X 20 X X$ \\ DOI: $10.1039 / b 000000 x$
}

\begin{abstract}
MEK and ERK are central components of the mitogen-activated protein kinase pathway. However, an accurate interaction has never been studied and accurate binding constants of the binary interaction have never been directly measured. In the present work, we studied the interaction between MEK and ERK by 10 stopped-flow fluorescence intensity and evaluated the association and dissociation rate constants $\left(\mathrm{k}_{\text {on }}\right.$ and $\mathrm{k}_{\text {off }}$ ) from the kinetic study. We compared the results obtained by using commercial and homemade protein productions. The dissociation binding constant $\left(\mathrm{K}_{\mathrm{d}}\right)$ value determined for the binding of MEK to ERK is in good agreement with the values obtained from the analysis of the kinase enzymatic reaction of previous in vitro studies.
\end{abstract}

\section{1. Introduction}

In the last two decades biological research has been focused on the exploration of the basis of cell regulation and function at molecular level. We now know that cell responses to external stimuli are determined by intracellular intricate signaling 20 networks, which are composed of biochemical pathways based essentially on protein interactions. Despite considerable progress has been made, it is apparent that the flow of biological information has not yet been fully deciphered. In particular the abundance of qualitative information, concerning cellular 25 interacting components, needs to be improved with sufficient availability of quantitative data. In this context, the set-up of approaches to provide high quality data in terms of the determination of kinetic parameters is needed to contribute to this kind of improvement. This is of special interest to systems 30 biologists who deal with the development of kinetic model of intracellular signal transduction and often suffer from the lack of available kinetic parameters.

Central building blocks in the intracellular signalling networks are the mitogen-activated protein kinase (MAPK) cascades which 35 are critical for cellular decision to proliferate, differentiate, or undergo apoptosis. ${ }^{1-3}$. MAPK cascades comprise several set of cytoplasmic protein kinases organized as modular pathways. The activation of upstream kinases by cell surface receptors leads to sequential activation of an evolutionarily conserved core module 40 of protein kinases (MAPKKK $\rightarrow$ MAPKK $\rightarrow$ MAPK). ${ }^{4}$ The most widely characterized mammalian MAPK cascade is the Raf-MEK-ERK axis (Fig. 1) along which multiple isoforms are present at each level. Among them, two high related isoforms, MEK1/2 and ERK1/2 play a primary role in signal transduction.

45 Although the MAPK cascades have been the subject of intense research, there are few quantitative kinetic studies on the components belonging to this pathway. In particular the association and dissociation rate constants (i.e., $k_{\text {on }}$ and $k_{\text {off }}$, respectively) for the binary protein-protein interactions in this 50 cascade have been derived from simulation/prediction studies ${ }^{5,6}$ or from in vitro studies of the kinase enzymatic reactions. ${ }^{7-9}$ There is only one recent work ${ }^{10}$ in which the dissociation binding constants $\left(K_{d}\right)$ concerning MAPK complexes have been estimated from measurements on living cells. Therefore in vitro accurate 55 determination of the kinetic parameters seems to be necessary to provide a more complete knowledge, allowing a direct comparison with the data obtained by different methodologies at the same time.

Numerous techniques have been described and applied to ${ }_{60}$ characterize protein-protein interactions in vitro. ${ }^{11-13}$ These techniques are often specialized and frequently use proper fluorescent probes as versatile means for studying the kinetics of protein interactions. Stopped-flow fluorescence intensity method offers a powerful tool for detailed kinetic analysis of protein ${ }_{65}$ interactions and has gained considerable importance during the past few years. ${ }^{14}$ The main advantages of this technique are the following: (i) the reaction can be monitored continuously in real time over a broad range of reactant concentrations at the millisecond time scale; (ii) the system operates in a liquid 70 environment where the interacting molecules are not bound to a solid support, this provides a more physiological condition of work, minimizing possible measurement alterations due to conformational changes that could arise from the protein-support binding; (iii) the experiments are not time-consuming.

75 The present study reports the kinetic investigation of the interaction between MEK and ERK by stopped-flow fluorescence 


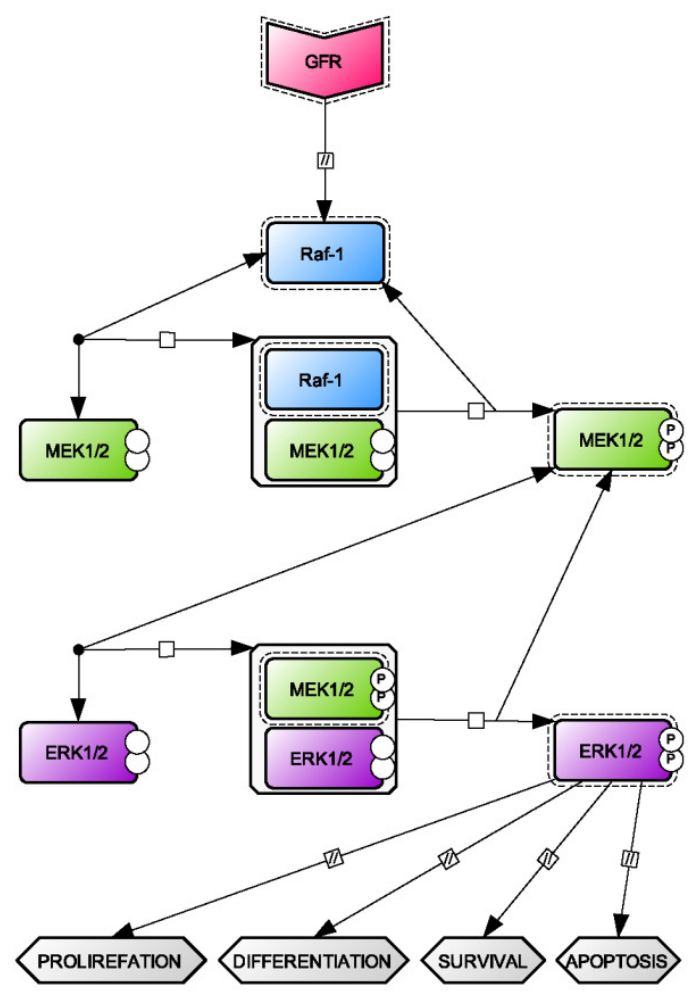

Fig. 1 Network topology of the mammalial MAP Kinases cascade: Raf/MEK/ERK axis. The signaling via this cascade, is usually initiated by growth factor receptor (GFR) activation, which transmit the signal by activating the MAPKKK, Raf-1. Active Raf-1 binds and activates the 5 MAPKK, MEK (two isoforms, MEK1/2), by phoshorylation. Following a similar process, active MEK binds and activates the MAPK, ERK (two isoforms, ERK1/2). Active ERK regulates various cellular processes such as proliferation, differentiation, survival, and apoptosis. The network topology was realized using Cell Designer software according to Systems 10 Biology Graphical Notation. ${ }^{33}$

intensity. The experimental procedure was based on the bioconjugation of ERK with a proper fluorophore, i.e. fluorescein-5-maleimide, followed by the analysis of its 15 interaction with MEK by stopped-flow. This approach was applied to study the interaction of both commercial and homemade recombinant MEK and ERK proteins. Here kinetic values for the $k_{\text {off }}$ and $k_{\text {on }}$ of MEK-ERK binding have been experimentally measured for the first time avoiding their 20 derivation from the analysis of the kinase enzymatic reaction. From the $k_{o f f} / k_{\text {on }}$ ratio we calculated the corresponding $K_{d}$ value that was compared with those obtained by previous studies.

\section{Experimental Procedures}

\subsection{Reagents}

25 The commercial recombinant MEK and ERK proteins used were full-length active MEK1 and full-length unactive ERK1. MEK1 was purchased from Upstate ${ }^{\circledR}$ as $N$-terminal GST and $C$-terminal 6His-tagged, expressed in E. coli, purified using glutathioneagarose followed by $\mathrm{Ni}^{2+} / \mathrm{NTA}$-agarose, activated using c-Raf 30 and re-purified using $\mathrm{Ni}^{2+} / \mathrm{NTA}$-agarose; purity $98 \%$; $\mathrm{MW}=71$ $\mathrm{kDa}$. ERK1 was purchased from Upstate ${ }^{\circledR}$ as $N$-terminal Glutathione S-transferase (GST)-tagged protein, expressed in $E$. coli and purified using glutathione-agarose; purity 97\%; $\mathrm{MW}=$ $70 \mathrm{kDa}$. The homemade recombinant MEK and ERK proteins 35 used were the constitutively active mutant MEK1 R4F (containing an N-terminal deletion of aa 32-51 and the Ser218Glu/Ser222Asp substitutions) and full-length unactive ERK2; both the proteins were produced in the laboratory of the authors as follows. MEK1 R4F and ERK2 were expressed in the 40 BL21-DE3 strain of E. coli transformed with pGEX-KG MEK1 R4F and NpT7-5 ERK2, respectively. MEK1 R4F (expressed as GST-fusion protein; MW $=66 \mathrm{kDa}$ ) and ERK2 (expressed with 6 His-tag; $\mathrm{MW}=42 \mathrm{kDa}$ ) were purified as described in detail previously; ${ }^{15}$ minimum $90 \%$ purity as determined by Sodium 45 Dodecyl Sulphate-PolyAcrylamide Gel Electrophoresis (SDSPAGE) and Coomassie blue (Bio-Safe Coomassie, Bio-Rad) staining. Purified MAP Kinases were dialyzed against Dulbecco's Phosphate-Buffered Saline (PBS; BE17-512F; BioWhittaker/Cambrex) using Slide-A-Lyzer 3.5K (PIERCE). 50 MEK1 R4F and ERK2 concentrations were determined after resolving recombinant protein samples and dilution series of purified $2 \mathrm{mg} / \mathrm{ml}$ bovine serum albumin by SDS-PAGE and staining with Coomassie blue; the gels were then documented using ChemiDoc XRS charged-coupled device (Bio-Rad) and the

55 proteins were quantified using Quantitative One software (Bio$\mathrm{Rad})$.

ERK2 and MEK1 R4F expression plasmids were a generous gift of Melanie Cobb (University of Texas, Southwestern) and Natalie Ahnn (University of Colorado, Boulder), respectively.

60 Fluorescein-5-maleimide was synthesised as reported previously. $^{16}$

\subsection{Bioconjugation}

ERK proteins have been bioconjugated with fluorescein-5maleimide following the reported protocol. ${ }^{17,18}$ ERK 65 concentration was $0.4 \mathrm{mg} / \mathrm{ml}$ and the excess of fluorescein-5maleimide used was 50-fold. After bioconjugation, the derivative was immediately purified using Sephadex ${ }^{\circledR}$ G-25 desalting column (Amersham Bioscience) and PBS ( $\mathrm{pH}=7.4)$ as eluent.

\subsection{Calculation of Dye/Protein ratio}

70 To evaluate the fluorophore labeling efficiency, the dye/protein ratios $(D / P)$ of the conjugates were determined by the absorption spectra of the labeled proteins, registered in PBS $(\mathrm{pH}=7.4)$ according to the relationship reported in eqn (1):

75

$$
D / P=\frac{A_{\max } \cdot \varepsilon_{\text {prot }}}{\left(A_{280}-c A_{\max }\right) \cdot \varepsilon_{d y e}}
$$

where $A_{280}$ is the absorption of the conjugate at $280 \mathrm{~nm} ; A_{\max }$ is 80 the absorption of the conjugate at the absorption maximum of the corresponding fluorescein-5-maleimide; $c$ is a correction factor which must be used to adjust for amount of $A_{280}$ contributed by the dye because fluorescent dyes also absorb at $280 \mathrm{~nm}$ and equals the $A_{280}$ of the dye divided by the $A_{\max }$ of the dye ( $c=$ $850.29) ; \varepsilon_{\text {prot }}\left(42230 \mathrm{~cm}^{-1} \mathrm{M}^{-1}\right)$ and $\varepsilon_{\text {dye }}\left(63096 \mathrm{~cm}^{-1} \mathrm{M}^{-1}\right)$ are the molar extinction coefficients for the protein used and fluorescein5 -maleimide, respectively. The evaluation of $c, \varepsilon_{\mathrm{dye}}$ and $\varepsilon_{\text {protein }}$ were calculated as reported elsewhere. ${ }^{19,20}$ 
ERK presents ten cysteine residues and the resulting $D / P$ value was 0.98 for both commercial and homemade proteins on the basis of three averaged bioconjugations.

\subsection{Experimental techniques}

${ }_{5} \mathrm{UV}-\mathrm{V}$ is measurements for the evaluation of the fluorophore labeling efficiency were recorded using a Shimadzu UV-1700 Pharma Spec Spectrophotometer equipped with $1.0 \mathrm{~cm}$ path length quartz cells.

Fluorescence kinetics measurements were recorded using an 10 Applied Photophysics SX20 stopped-flow spectrometer fitted with a $515 \mathrm{~nm}$ cut-off filter between the cell and fluorescence detector and equipped with a thermostat bath $\left(30^{\circ} \mathrm{C}\right)$. Data acquisition, visualisation and analysis were provided by Pro-Data software from Applied Photophysics Ltd.

\section{2.5 Experimental procedures}

Biolabelled ERK concentration (10 $\mathrm{nM}$ in PBS) was kept constant and several shots of different MEK concentrations were performed: $100 \mathrm{nM}, 120 \mathrm{nM}, 140 \mathrm{nM}$ and $160 \mathrm{nM}$ in PBS for the commercial proteins. For homemade production, the chosen ${ }_{20}$ MEK concentrations were: $20 \mathrm{nM}, 40 \mathrm{nM}, 60 \mathrm{nM}, 100 \mathrm{nM}$ and $130 \mathrm{nM}$. The reported concentrations are syringe concentrations, this means that the real concentrations in the cuvette are halved. Each experiment (whole concentration set) was repeated five times, each time using a new mother solution and a different set 25 of protein production. For each dilution condition at least five scans were acquired and averaged. Each experimental point is therefore an average of 25 shots. Raw data were analyzed and plotted to a single exponential function by using Pro-Data Viewer 4.0.17 and from this data treatment the observed rate constants $30\left(k_{\text {obs }}\right)$ were obtained. The excitation wavelength was $495 \mathrm{~nm}$ and slits widths of the excitation monochromator were $0.2 \mathrm{~mm}$.

The displacement experiment was performed according to Eccleston et al. ${ }^{21}$ A solution containing a mixture of $50 \mathrm{nM}$ biolabelled ERK with $50 \mathrm{nM}$ MEK was rapidly mixed with a 35 large excess (400 nM) of unlabelled ERK. The displacement was repeated four times and the $k_{\text {off }}$ obtained is an averaged value of these four experiments.

\section{Results}

To study the interaction between MEK and ERK we firstly used 40 the commercial proteins. The binary protein binding was investigated under pseudo-first order conditions (i.e., [MEK] >> [ERK]). Fig. 2 shows that on mixing $10 \mathrm{nM}$ ERK with $120 \mathrm{nM}$ MEK there is a decrease in fluorescence intensity which can be well fitted to give a rate constant of $12.49 \mathrm{~s}^{-1}$.

45 The dependence of the $k_{o b s}$ for MEK-ERK binding was investigated using $10 \mathrm{nM}$ biolabelled ERK and the range of 100$160 \mathrm{nM}$ MEK (Fig. 3). In these experimental settings, the values of the kinetic parameters can be calculated from the slopes and intercepts of the linear plots of $k_{o b s}$ versus increasing 50 concentration of MEK (see eqn 2).

$$
k_{o b s}=k_{o n}[M E K]+k_{o f f}
$$

A

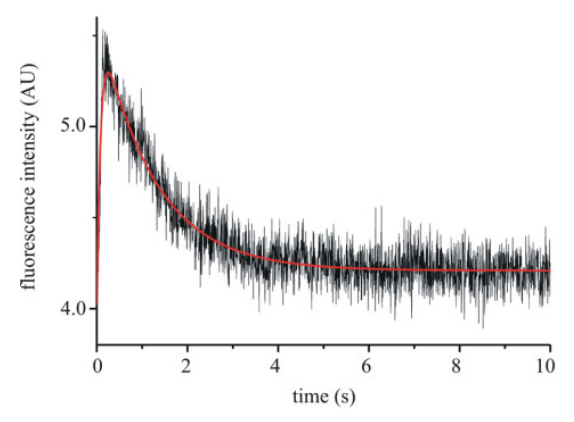

B

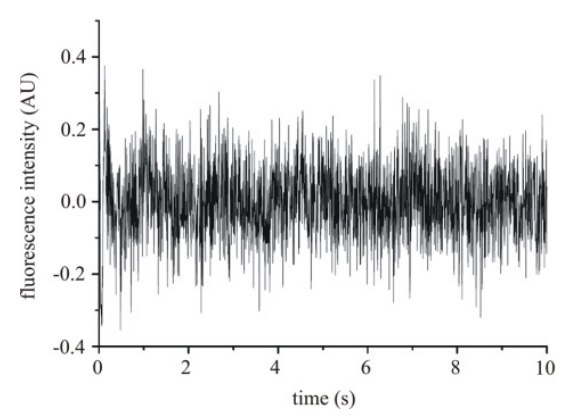

${ }_{55}$ Fig. 2 (A) Stopped-flow fluorescence intensity record of the binding of $120 \mathrm{nM}$ MEK to $10 \mathrm{nM}$ ERK (commercial proteins). The solid thin line is the best fit to the data giving rate constants of $12.49 \mathrm{~s}^{-1}$. (B) Residuals are also reported.

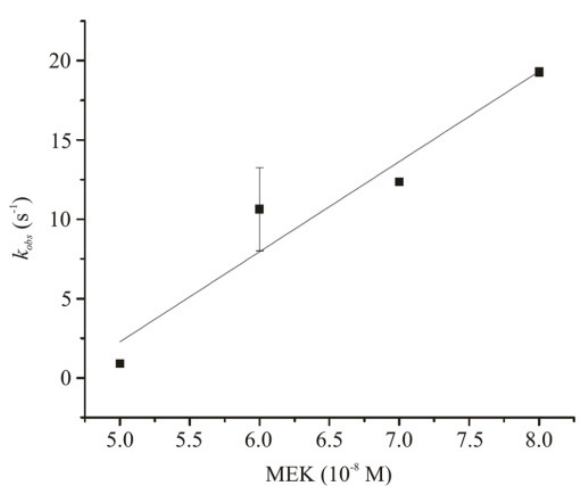

Fig. 3 Dependence of the $k_{o b s}$ determined by fluorescence intensity of the binding of ERK to increasing MEK concentrations (commercial proteins). Data points are the mean of five independent experiments \pm standard 65 deviation. Error bars not visible are concealed by the data point.

In particular, the slope of the straight line is the $k_{\text {on }}$ (secondorder rate constant; units, $\mathrm{M}^{-1} \mathrm{sec}^{-1}$ ) and the intercept on the ordinate is the $k_{\text {off }}$ (first-order rate constant; units, $\mathrm{sec}^{-1}$ ). The 70 second-order rate constant $k_{\text {on }}$ is $5.49 \cdot 10^{8} \mathrm{M}^{-1} \mathrm{~s}^{-1}$. As it can be seen, the intercept on the ordinate has a small negative value (-24 $\left.\sec ^{-1}\right)$. This shows that the interaction is nearly completely shifted toward the formation of the complex. 


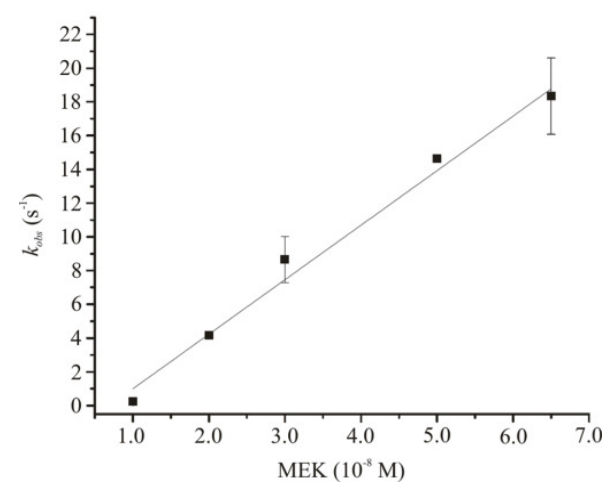

Fig. 4 Dependence of the $k_{o b s}$ determined by fluorescence intensity of the binding of ERK to increasing MEK concentrations (homemade proteins). Data points are the mean of five independent experiments \pm standard 5 deviation. Error bars not visible are concealed by the data point.

$\left.\sec ^{-1}\right)$. This shows that the interaction is nearly completely shifted toward the formation of the complex.

To further investigate this aspect, we then used more cheap 10 homemade proteins in order to perform other interactions and to carefully evaluate the $k_{\text {off }}$ value. The interaction was repeated and the dependence of the $k_{o b s}$ for MEK-ERK binding was again investigated using $10 \mathrm{nM}$ biolabelled ERK and a range of 20-130 nM MEK (Fig. 4). The slope of the straight line through the 15 points gives the apparent $k_{\text {on }}$ value and this is estimated to be $3.23 \cdot 10^{8} \mathrm{M}^{-1} \mathrm{~s}^{-1}$ which is in good accordance with the previous value obtained with commercial proteins. The intercept of the straight line with the $y$-axis should give the $k_{\text {off }}$ value, but again it cannot be reliably distinguished from zero with the obtained data

20 It should be noted that there will be a significant error on the points at low concentrations, since true pseudo-first-order conditions did not prevail. The intercept would not be reliable even if seen to be finite but small.

Since disassociating rate constant value seems to be small, 25 obtained $k_{\text {off }}$ is not reliable. To gain more information and to measure $\mathrm{k}_{\text {off }}$ value accurately, a displacement experiment was executed as proposed previously. ${ }^{21}$ Briefly, in the displacement experiment (see Scheme 1), a solution containing fluorescent ERK (ERK-fL) and MEK is mixed with an excess of non-

30 fluorescent ERK (ERK-nfL). The concentration of ERK-fL is chosen to get a saturation of MEK, and then a high concentration of ERK-nfL is added so that ERK-fL dissociates from MEK and cannot reassociate. In this way the rate constant of the observed process is determined only by $k_{-l}$.

35 The $k_{\text {off }}$ value was therefore measured directly by displacement of ERK from its complex with MEK using an excess of unlabeled ERK. Fluorescence intensity was monitored during the process and the corresponding record was fitted to give an averaged rate constant of $18.7 \mathrm{~s}^{-1}$ (Fig. 5). This $k_{\text {off value }}$ 40 together with that obtained for the $k_{\text {on }}$ allowed us to calculate the $K_{\mathrm{d}}$ value of $58 \mathrm{nM}$ for MEK-ERK interaction. This is in excellent agreement with the $K_{\mathrm{d}}$ value of $50 \mathrm{nM}$ obtained by steady-state fluorescence in the same buffer (data not shown).

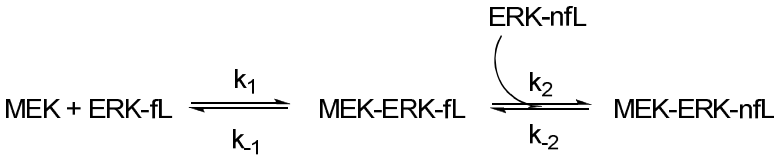

Scheme 1 Displacement reaction.

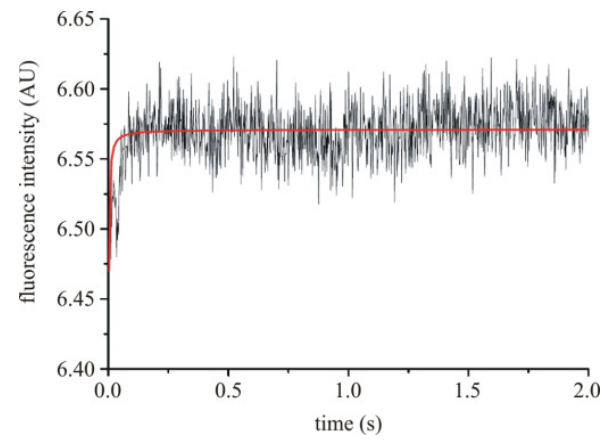

Fig. 5 Stopped-flow fluorescence record of a representative displacement experiment (homemade proteins): one syringe contained $50 \mathrm{nM}$ 50 biolabelled ERK, $50 \mathrm{nM}$ MEK, and the other syringe contained $400 \mathrm{nM}$ unlabelled ERK. The plot shows a fit to a single exponential with a rate constant of $20.5 \mathrm{~s}^{-1}$. The experiment was repeated four times and the averaged obtained value is $18.7 \mathrm{~s}^{-1} \pm 2.2$.

\section{Discussion}

${ }_{55}$ In the present work, the binding between MEK and ERK, two members of a crucial intracellular signal pathway, was studied by stopped-flow fluorescence intensity. The values of $k_{\text {on }}$ and $k_{\text {off }}$ were experimentally measured for the first time avoiding their derivation from the analysis of the kinase enzymatic reaction. The ${ }_{60} K_{d}$ value was determined from the $\mathrm{k}_{\text {off }} / \mathrm{k}_{\text {on }}$ ratio and results to be in excellent agreement with the values obtained in previous in vitro studies. ${ }^{8,9}$ This shows that the use of stopped-flow technique is a suitable approach for studying protein-protein interactions in vitro.

65 A careful collection of available information, relative to the kinetic parameter for MEK-ERK interaction, allowed us to compare the values obtained with those previously found by different methods (Table 1). In fact, the $K_{d}$ value reported is of the same order of magnitude of that obtained by deriving $k_{o n}$ and $70 k_{\text {off }}$ from the in vitro study of the kinase enzymatic reaction. ${ }^{7-9}$ Compared to those obtained by in vitro methods, the $K_{d}$ values derived from simulation modeling by the group of Schoeberl ${ }^{5}$ and Yamada $^{7}$ result to be one and two order of magnitude different, respectively. The in vitro $K_{d}$ value results to be one order of 75 magnitude different from that obtained in vivo by Fujioka and coworkers. ${ }^{10}$ The authors calculated the half-life of the MEK-ERK complex, and estimated the dissociation rates from these halflives.

${ }_{80}$ Table 1 Parameters for MEK-ERK interaction.

\begin{tabular}{lllll}
\hline references & method & $k_{\text {on }}\left(10^{6} \mathrm{M}^{-1} \mathrm{~s}^{-1}\right)$ & $k_{\text {off }}\left(\mathrm{s}^{-1}\right)$ & $K_{d}(\mathrm{nM})$ \\
\hline This study & in vitro & 323 & 18.7 & 58
\end{tabular}

45 


\begin{tabular}{|c|c|c|c|c|}
\hline $\begin{array}{l}\text { Bhalla } 2004^{a, 8}, \\
\text { Sasagawa et al. } \\
2005^{a, 9}\end{array}$ & in vitro & 16.2 & 0.6 & 37 \\
\hline $\begin{array}{l}\text { Fujioka et al. } \\
2006^{10}\end{array}$ & in vivo & 0.88 & 0.088 & 100 \\
\hline $\begin{array}{l}\text { Schoeberl et al. } \\
2002^{5}\end{array}$ & $\begin{array}{l}\text { simulation } \\
\text { modeling }\end{array}$ & 0.11 & 0.033 & 300 \\
\hline $\begin{array}{l}\text { Yamada et al. } \\
2004^{6}\end{array}$ & $\begin{array}{l}\text { simulation } \\
\text { modeling }\end{array}$ & 0.318 & 0.9 & 2800 \\
\hline
\end{tabular}

${ }^{a}$ Considering the Michaelis-Menten formulation as a special case of two reactions in sequence (Bhalla \& Iyengar 1999), the values corresponding to $K_{m}, k_{\text {cat }}$ and $k_{\text {off }} / k_{\text {cat }}$ ratio (available in the DOQS database, http://doqcs.ncbs.res.in) for MEK-ERK kinase enzymatic reaction allowed the derivation of the values corresponding to $k_{o n}, k_{\text {off }}$ and $K_{d}$ for MEK-ERK binding.

In the context of protein-protein interaction it is well established that the in vitro study requires in vivo validation, and vice versa. Measures performed in living cells have to be 5 considered of high value due to the physiological/cellular context in which molecules operate. On the other hand, in vitro methods analyze binary protein-protein interactions in a cell free system, which is characterized by the absence of positive or negative influence exerted by additional molecular determinants which 10 could be present in vivo. Therefore, significant discrepancies may arise from the two approaches. Apparently any remarkable difference in the readout is daunting. Indeed, if it occurs, it may be considered as an indication of a possible gap in the biological information and therefore this suggestion may be considered as 15 useful. Taking into account these considerations, we may attempt to speculate on the comparison between the $\mathrm{K}_{\mathrm{d}}$ values obtained in vitro and the value derived from the in vivo study reported by Fujioka and coworkers. The observed difference in one order of magnitude among these $K_{d}$ may be due to the diverse activation 20 state of MEK as well as the presence of additional factors regulating MEK-ERK interaction in vivo. Indeed, as reported by the group of Fujioka, ${ }^{10}$ only a fraction of MEK is activated in vivo, even when ERK activation is saturated, whereas all of the MEK is in the activated form in vitro. In addition, a number of 25 evidence suggests the emerging role of scaffold proteins as regulators of MAPK signaling kinetics in terms of both potentiation and attenuation. ${ }^{22-24}$

It is well known that MEK-ERK interaction and signaling represents a complex signal module that may be controlled by 30 different regulatory mechanisms. MEK is activated by phosphorylation of two Ser residues (Ser218 and Ser222 in MEK1; Ser222 and Ser226 in MEK2), and in turn binds and activates ERK by dual phosphorylation on Thr and Tyr residues (Thr202 and Tyr204 in ERK1; Thr185 and Tyr187 in ERK2).

35 Moreover, inactive MEK can also bind (albeit weakly) to ERK and the phosphorylation of additional MEK amino acid residues have been reported in literature to have positive and negative effects on ERK phosphorylation and signaling. ${ }^{25-27}$ Therefore, one may speculate that the different phosphorylated residues play 40 a role in regulating MEK-ERK binding affinity.

Interestingly, it is a controversial issue whether phosphorylation of ERK by MEK is a processive or distributive mechanism. In a processive catalysis, after binding the substrate, the kinase carries out two phosphorylation before releasing the 45 final product; in contrast, in a distributive mechanism, the enzyme releases the intermediate monophosphorylated products, and a new collision is required for the conversion of this intermediate into the final product. ${ }^{28}$ However, a number of evidence demonstrates that dual phosphorylation of MAPKs 50 occurs through a distributive two-collision mechanism. ${ }^{29-31}$ In this case, the $K_{d}$ values that we calculated from our in vitro measurements would represent the $K_{d}$ corresponding to MEKERK complex formation that precedes the first step of the distributive mechanism of catalysis. Interestingly, the obtained $K_{d}$ 55 value is in excellent agreement with the corresponding value (50 $\mathrm{nM})$ that is possible to calculate from the $k_{\text {on }}$ and $k_{\text {off }}$ reported by Markevich et al. ${ }^{28}$ They developed a computational model of MAPK signaling based on parameter values retrieved from previously reported experimental data on the time course of ${ }_{60}$ MEK-catalyzed dual phosphorylation of ERK. For a future detailed characterization of MEK-ERK binding in this context, it will be interesting to analyze the interaction between MEK and monophosphorylated ERK using the proposed stopped-flow approach and compare the derived data with those reported in the ${ }_{65}$ case of MEK binding to unphosphorylated ERK.

A recent study by Baccarini et al. reports that MEK1-MEK2 heterodimers exist in the cells, and that they coesist with MEK1 and MEK2 monomers, with higher order complexes and possibly with homodimers. ${ }^{32}$ In this context, the role of heterodimer 70 formation has been shown to be essential for ERK-mediated phosphorylation of Thr292 of MEK1, that attenuates MEK/ERK signaling through a negative feed-back mechanism. ${ }^{32}$

\section{Conclusions}

Through the case study of MEK-ERK binding, we propose the 75 stopped-flow approach as a suitable in vitro method to experimentally measure the kinetic parameters of binary proteinprotein binding in a well-characterized and not time-consuming manner. This is of particular importance in the development of signal transduction mathematical models, in which the systems 80 biologists are often faced with the difficulties concerning the choice of the kinetic constant values to be used in the model of interest. A more intensive use of stopped-flow fluorescence intensity technique may facilitate the generation of high-quality in vitro data. Having established a framework for deriving such 85 valuable data, the natural extension of our work may consist in the kinetic analysis from a biological standpoint more closely to the real complex systems of MAPK cascade. This may be achieved by investigating the in vitro MEK-ERK interaction considering homodimer $v s$ heterodimer formation as well as the 90 presence/absence of specific phosphorylated amino acid residues in the recombinant proteins of interest.

Finally, the stopped-flow approach that we proposed may be applied in the context of binary protein-protein interaction belonging to other signaling cascades and contribute to a better 95 comparison between in vitro and in vivo protein interaction behaviors, leading to an improvement in the development of signal transduction models for a fine elucidation of cell signaling mechanisms. 


\section{Acknowledgements}

We thank Melanie Cobb (Univerity of Texas, Southwestern) and Natalie Ahnn (University of Colorado, Boulder) for providing ERK2 and MEK1 R4F expression plasmids. NB thanks the late ${ }_{5}$ Prof. John F. Eccleston for his teaching on kinetics and stoppedflow.

\section{Notes and references}

${ }^{a}$ Department of General Chemistry and Organic Chemistry and NIS, Interdepartmental Centre of Excellence, University of Torino, Corso M. 10 d'Azeglio 48, 10125 Torino, Italy. Fax: +39-011-236-7596; Tel: +39-

011-670-7596; E-mail: nadia.barbero@unito.it

${ }^{b}$ Department of Oncological Sciences, Institute for Cancer Research and Treatment, University of Torino, Strada Provinciale 142, Km 3.95, 10060 Candiolo (TO), Italy. Fax: +39 011-9933524; Tel: +39 011-9933507; E15 lucia.napione @unito.it

${ }^{c}$ Department of Drug Science and Technology, University of Torino, Via P. Giuria 9, 10125 Torino, Italy.

\$ These authors contributed equally to this work

201 M. Raman and M.H. Cobb, Curr. Biol., 2003, 13, R886.

2 K. Kuida and D.M. Boucher, J. Biochem., 2004, 135, 653.

3 L. Chang and M. Karin, Nature, 2001, 410, 37.

4 M.G. Wilkinson and J.B. Millar, FASEB J., 2000, 14, 2147.

5 B. Schoeberl, C. Eichler-Jonsson, E.D. Gilles and G. Muller, Nat. Biotechnol., 2002, 20, 370.

6 S. Yamada, T. Taketomi and A. Yoshimura, Biochem. Biophys. Res. Commun., 2004, 314, 1113.

7 U.S. Bhalla and R. Iyengar, Science, 1999, 283, 381.

8 U.S. Bhalla, Biophys. J., 2004, 87, 745.

309 S. Sasagawa, Y-I Ozaki, K. Fujita and S. Kuroda, Nat. Cell Biol., $2005,7,365$.

10 A. Fujioka, T. Terai, R.E. Itoh, K. Aoki, T. Nakamura, S. Kuroda, E. Nishida and M. Matsuda, J. Biol. Chem., 2006, 281, 8917.

11 J.H. Lakey and E.M. Raggett, Curr. Opin. Struct. Biol., 1998, 8, 119.

3512 E.M. Phizicky and S. Fields, Microbiol. Rev., 1995, 59, 94.

13 Haian Fu Protein-Protein Interactions: Methods and Applications Methods in Molecular Biology, 2004, Vol. 261, Humana Press.

14 M.G. Gore and S.P. Bottomley, Stopped-flow Fluorescence Spectroscopy. In Spectrophotometry \& Spectrofluorimetry, 2000, M.G. Gore Ed., Oxford University Press.

15 C.J. Heise and M.H. Cobb, Methods, 2006, 40, 209.

16 P.Y. Reddy, S. Kondo, S. Fujita, and T. Toru, Synthesis, 1998, 7, 999.

17 G.T. Hermanson, Bioconjugate Techniques, $2^{\text {nd }}$ edition, 2008, Academic Press.

18 N. Barbero, L. Napione, P. Quagliotto, S. Pavan, C. Barolo, E. Barni, F. Bussolino and G.Viscardi, Dyes and Pigments, 2009, 83, 225.

19 S.C. Gill and P.H. von Hippel, Anal. Biochem., 1989, 182, 319.

20 C.N. Pace, F. Vajdos, L. Fee, G. Grimsley and T.Gray, Protein Sci., 1995, 4, 2411.

21 J.F Eccleston, J.P. Hutchinson and H.D. White, Protein-ligand interactions, structure and spectroscopy: a practical approach, 2001, S.E. Harding \& B.Z. Chowdhry Editors, Oxford University Press.

22 M.M. McKay, D.A. Ritt and D.K. Morrison, Proc. Natl. Acad. Sci. USA, 2009, 106, 11022.

23 M. Roy, Z. Li and D.B. Sacks, Mol. Cell. Biol., 2005, 25, 7940.

24 C. Sharma, T. Vomastek, A. Tarcsafalvi, A.D. Catling, H.J. Schaeffer, S.T. Eblen and M.J. Weber, J. Cell. Biochem., 2005, 94, 708.

6025 A. Brunet, G. Pages and G. Pouysségur, FEBS Letters, 1994, 346, 299.

26 S. T. Eblen, J. K. Slack-Davis, A. Tarcsafalvi, J. T. Parsons, M. J. Weber and A. D. Catling, Mol. Cell. Biol., 2004, 24, 2308.

27 J. K. Slack-Davis, S. T. Eblen, M. Zecevic, S. A. Boerner, A

65 Tarcsafalvi, H. B. Diaz, M. S. Marshall, M. J. Weber, J. T. Parsons and A. D. Catling, J. Cell Biol., 2003, 162, 281.
28 N. I. Markevich, J. B. Hoek and B. N. Kholodenko, J. Cell Biol., 2004, 164, 353.

29 W. R. Burack and T. W. Sturgill, Biochemistry, 1997, 36, 5929.

7030 J. E. Jr. Ferrell and R. R. Bhatt, J. Cell Biol., 1997, 272, 19008.

31 Y. Zhao and Z.-Y. Zhang, J. Cell Biol., 2001, 276, 32382.

32 F. Catalanotti, G. Reyes, V. Jesenberger, G. Galabova-Kovacs, R. de Matos Simoes, O. Carugo and M. Baccarini, Nat. Struct. Mol. Biol., 2009, 16, 294.

7533 N. Le Novère, M. Hucka, H. Mi, S. Moodie, F. Schreiber, F. Sorokin, E. Demir, K. Wegner, M.I. Aladjem, S.M. Wimalaratne, F.T Bergman, R. Gauges, P. Ghazal, H. Kawaji, L. Li, Y. Matsuoka, A. Villéger, S.E. Boyd, L. Calzone, M. Courtot, U. Dogrusoz, T.C.Freeman, A. Funahashi, S. Ghosh, A. Jouraku, S. Kim, F.

80 Kolpakov, A. Luna, S. Sahle, E. Schmidt, S. Watterson, G. Wu, I Goryanin, D.B. Kell, C. Sander, H. Sauro, J.L. Snoep, K. Kohn and H. Kitano, Nat. Biotechnol., 2009, 27, 735 . 